\title{
Glycosylated Hemoglobin as a Predictor of Sepsis and All-Cause Mortality in Trauma Patients
}

\section{Feng Guo \\ Haitao Shen (1)}

Department of Emergency Medicine, Shengjing Hospital of China Medical University, Shenyang, People's Republic of China
Correspondence: Haitao Shen Department of Emergency Medicine, Shengjing Hospital of China Medical

University, No. 36 Sanhao Street, Heping

District, Shenyang, I 10004, People's

Republic of China

Tel +86-24-966I5-64l3।

Email pianzhang6@163.com
Background and Purpose: Infection is a common comorbidity and cause of death in emergency trauma patients, especially in diabetic patients. Once the patients are admitted, they are more susceptible to further complications like sepsis and resultant increase in inhospital mortality. Therefore, it is necessary to evaluate risk factors associated with sepsis after trauma and death in trauma patients.

Methods: A total of 397 trauma patients were divided into 2 groups according to HbA1c level, HbA1c: $<6.5 \%(n=259)$, HbAlc: $>6.5 \%(n=138)$, and baseline clinical characteristics were collected. The independent risk factors of sepsis associated with trauma were screened using univariate and multivariate logistic regression analysis. Cox proportional hazards regression analysis was used to investigate risk factors for 30-day all-cause mortality.

Results: The sepsis incidence $(76.1 \%$ vs $35.9 \%, \mathrm{P}<0.001)$ and mortality rate $(29.7 \%$ vs $7.3 \%, \mathrm{P}<0.001)$ were significantly higher in $\mathrm{HbA} 1 \mathrm{c}>6.5 \%$ group. Multivariate logistic regression analysis revealed that the independent risk factors of sepsis after trauma were diabetes (OR: 3.1, 95\% CI: 1.41-6.79), hypertension (OR: 2.55, 95\% CI: 1.35-4.82), coagulation disorder (OR: 3.45, 95\% CI: 1.23-9.67), creatinine (OR: 3.71, 95\% CI: $1.66-$ 8.31), urea nitrogen (OR: 0.96, 95\% CI: 0.92-0.99), HbA1c\%>6.5 (OR: 2.05, 95\% CI: $1.65-$ 2.54 ), increase in body mass index (OR: 1.08, 95\% CI: 1.03-1.13) and lower initial GCS score (OR: 0.93, 95\% CI: 0.88-0.99). Multivariable Cox proportional hazard analysis revealed that male (HR: 1.94, 95\% CI: 1.21-3.12), HbAlc >6.5\% (HR: $1.45,95 \% \mathrm{CI}$ : 1.32-1.6), albumin (HR: 0.54, 95\% CI: 0.34-0.86), creatinine (HR: 1.02, 95\% CI: $1.01-$ 1.03), APTT (HR: 1.02, 95\% CI: 1.01-1.03), SOFA score (HR: 1.2, 95\% CI: 1.1-1.31), age $>65$ years (HR: $3.21,95 \%$ CI: 1.95-5.3) were independent risk factor for trauma patients' mortality.

Conclusion: The prevalence of sepsis and mortality was higher in trauma patients with $\mathrm{HbA} 1 \mathrm{c}>6.5 \%$. HbA1c was independent risk factor for sepsis and all cases of mortality in trauma patients.

Keywords: trauma, sepsis, glycosylated hemoglobin, diabetes, mortality, emergency

\section{Introduction}

To date, trauma still exerts a significant burden for health care systems worldwide and is one of the most common injuries managed in the emergency department. Within the United States, trauma is the primary cause of mortality in individuals younger than $45 .{ }^{1}$ For patients who do not need surgical intervention or have been admitted to hospital after surgery, most of them need to continue treatment in the emergency intensive care unit (EICU). During EICU treatment, complications after trauma including sepsis, multiple organ failure (MODS) and other late trauma complications increase the probability of a poor prognosis and 
mortality. ${ }^{2}$ A large sample of studies has been conducted to explore the risk factors of post-traumatic sepsis, but its research variables are directly related to trauma, such as the number of trauma sites, blood transfusion, etc. without considering the basic state of the patient. ${ }^{3}$ Current studies have shown that diabetics, especially those with poor blood glucose control, are more likely to develop infectious diseases than non-diabetic patients. ${ }^{4}$ Therefore, it is necessary to explore the risk factors of post-traumatic infection in diabetic patients. At present, a few studies have made preliminary exploration into the matter, and are mainly limited to specific surgical studies. ${ }^{5}$ The specific analysis of sepsis after trauma in patients with poor blood glucose control has not been reported. Glycosylated hemoglobin (HbAlc) is a common indicator of long-term glycemic control; this is mainly because red blood cells live for 120 days, which reflects blood sugar levels for the first 120 days. Therefore, it is often used as an indicator of long-term control of blood glucose in diabetic patients, or used to assess the prognostic risk of other diseases. Previous studies have found that $\mathrm{HbA} 1 \mathrm{c}$ levels are associated with increased mortality within a period of 6 months and poor neurological outcomes in out-ofhospital cardiac arrest survivors. ${ }^{6,7}$ In addition, HbAlc levels are not affected by acute attacks of illnesses; as a result, it is a reliable marker to determine the presence of hyperglycemia before onset. We speculate that $\mathrm{HbAlc}$ levels may be a reliable predictor for sepsis and probable increased mortality for trauma patients. Therefore, this study aims to evaluate the relationship between $\mathrm{HbAlc}$ levels with effect to sepsis and all-cause mortality in trauma patients. ${ }^{8}$

\section{Information and Methods Research Design and Data Collection}

This retrospective study was conducted at Shengjing Hospital affiliated to China Medical University. We use electronic medical records and paper medical records, from 1st January 2015 to 31st December 2020. We extracted data on trauma patients in EICU; concentrating on four parts.

1. Demographic data: age, sex, BMI.

2. Vital signs, SOFA score, GCS score and complications.

3. Blood gas, lactic acid, serum creatinine, coagulation index and HbA1c.
4. Primary outcome: 30-day mortality, Sepsis incidence; Secondary outcome: length of EICU days, total length of hospitalization.

Only patients who completed the HbAlc examination were included in the study. For patients with a history of multiple admissions, we focused on the data that was provided by the first admission. The remaining exclusion criteria are: Patients who presented with sepsis at the time of admission to the EICU; age less than 18 years old; the length of hospital stay in EICU was less than 24 hours; automatic discharges. We conformed to the definition and description of sepsis that was provided by the Third International Consensus Definitions for Sepsis and Septic Shock (sepsis-3). ${ }^{9}$ Our study utilized the anonymous data available from electronic medical records and paper medical records; hence, the requirement for informed consent was waived. In summary, the study complied with the ethical standards laid down in the 1964 Declaration of Helsinki and its later amendments.

\section{Statistical Analysis}

The Continuous variables were expressed as mean (standard deviation) or median (IQRs), and classified variables were expressed as total and percentage. The KolmogorovSmirnov test was used to test normality. Differences between the two groups were analyzed using the Student's $t$-test or Mann-Whitney $U$-test, while the Chisquare test with Fisher's exact test were used for categorical variables. The odds ratio (ORs) or hazard ratio (HRs) within $95 \%$ confidence intervals were used to compare the data in univariate analysis. Variables were considered as candidates for inclusion in the multivariate model if the associated univariate $p$ value was $<0.05$. A logistic regression model, adjusted for $\mathrm{HbAlc}$-associated variables and sepsis-associated variables, was constructed to identify independent variables that predicted sepsis occurs. A Cox proportional hazards regression model, adjusted for HbAlc-associated variables and 30-day mortalityassociated variables, was constructed to identify independent variables that predicted 30-day mortality. Kaplan-Meier analysis was used to test the association between 30-day mortality and HbAlc using $6.5 \%$ as the cut-off point. SPSS software version 23.0 (SPSS Inc., Chicago), is used for all data analysis. Statistical significance was set to $\mathrm{P}<0.05$. 


\section{Results}

\section{Baseline Demographic and Clinical Characteristics Data}

A total of 528 consecutive patients were admitted to the medical EICU due to trauma between 1st January 2015 to 31st December 2020, of whom 25 patients were excluded because length of stay in EICU was less than 24 hours; a further 42 patients were excluded because of age were under 18; 64 patients were excluded due to lack of HbA1c data (Figure 1). The remaining 397 patients were eligible for analysis and were divided into high HbA1c $(\mathrm{n}=259$, $65.2 \%)$ and low HbA1c $(\mathrm{n}=138,34.8 \%)$ groups using HbA1c $6.5 \%$ as the cut-off point.

We summarize the demographic, mortality and sepsisrelated data shown in Table 1. There were 114 patients older than 65 years, accounting for $28.7 \%$, and $76.7 \%$ of the patients were male. The SOFA score and BMI were 8 $(3,15)$ and $26.90(24.20,30.25)$, respectively. The most common underlying comorbidities were hypertension (26.4\%), alcohol abuse (16.4\%) and diabetes (15.9\%). Compared with the low HbA1c group, there was no statistically significant difference between the groups in inflammatory markers such as WBC and neutrophils with high HbA1c. As expected, those with high HbAlc had a higher SOFA score $[4(3,7)$ vs $4(2,5), p=0.011]$ and were more likely to have longer length of EICU stay [6(3, 12) vs $3(2,8) \mathrm{p}=0.001]$ compared with those in the low HbA1c group. The other variables appeared to be comparable between these two groups, except that those with high

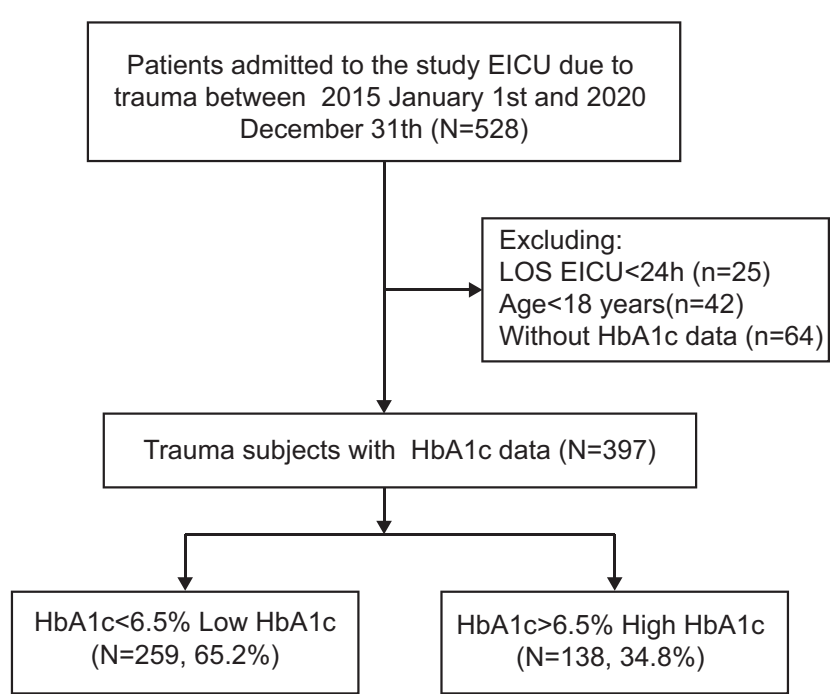

Abbreviations: LOS, length of stay; EICU, emergency intensive care unit; $\mathrm{HbA} 1 \mathrm{c}$, hemoglobin A1c

Figure I Flowchart of patient enrollment.
HbAlc were more likely to be male $(39.1 \%$ vs $23.2 \%$, $\mathrm{p}<0.001)$ compared to those in the low HbA1c group.

\section{Relationship Between High HbAlc and Sepsis and 30-Day All-Cause Mortality}

The incidence of sepsis in both groups was relatively high, but higher in the high HbA1c group than in low HbAlc group $(76.1 \%$ versus $35.9 \%, \mathrm{P}<0.001)$. Moreover, the 30 day mortality in the high HbAlc group was higher than that in the low HbA1c group $(29.7 \%$ versus $7.3 \%$, $\mathrm{P}<0.001$ ). Given the above results, we also investigated the relationship between $\mathrm{HbAlc}$ and the occurrence of sepsis and patient 30-day mortality.

We used logistic regression analysis to identify the factors that predicted sepsis exhibition after EICU admission. The univariate analysis showed that sepsis significantly associated with high $\mathrm{HbA1}$, BMI, age $>65$ and other factors shown in Table 2. Multivariable logistic regression using backward elimination showed that high $\mathrm{HbAlc}$ level (OR, 2.05; 95\% CI, 1.65-2.54) was independent predictors of sepsis, shown in Table 3.

Sixty of the 397 patients (15.1\%) died during EICU admission. We used Kaplan-Meier analysis to estimate the probability of survival during EICU admission according to the HbA1c level. Kaplan-Meier analysis along with the Log rank test showed that the survival period was significantly shorter in patients with an $\mathrm{HbA} 1 \mathrm{c}$ level $>6.5 \%$ than in those with an $\mathrm{HbA} 1 \mathrm{c}$ level $<6.5 \%(\mathrm{P}<0.001$; Figure 2).

We then used Cox proportional hazard analysis to identify the mortality risk factors. The univariate analysis showed that EICU mortality was significantly associated with $\mathrm{HbAlc}$ level $>6.5 \%$, gender, SOFA score and several factors shown in Table 4. Multivariable Cox proportional hazard analysis with backward elimination indicated that HbAlc level $>6.5 \%$ (HR, 3.21\% CI, 1.95-5.3; $\mathrm{P}<0.001$ ) was significant independent predictors of mortality, as well as gender, albumin, APTT in Table 5.

Synthesizing the above results, only $\mathrm{HbA} 1 \mathrm{c}>6.5 \%$ can be used as an independent risk factor for both sepsis and death in trauma patients.

\section{Discussion}

The risk factors associated with sepsis and death in trauma patients vary. According to our study, univariate analysis results showed that $\mathrm{PH}$, albumin and hemoglobin on admission were risk factors for mortality of emergency trauma patients, which was consistent with the results of some previous studies. Acidosis is an established risk 
Table I Demographic and Clinical Characteristics of Patients Included

\begin{tabular}{|c|c|c|c|c|}
\hline $\begin{array}{l}\text { Characteristics n (\%) } \\
\text { [Mean(SD) or Median, IQR] }\end{array}$ & $\begin{array}{l}\text { Overall } \\
(n=397)\end{array}$ & $\begin{array}{c}\text { Low HbAlc } \\
\text { HbAlc }<6.5 \% \\
(n=259)\end{array}$ & $\begin{array}{c}\text { High HbAlc } \\
\text { HbAlc }>6.5 \% \\
(n=138)\end{array}$ & $p$ \\
\hline \multicolumn{5}{|l|}{ Demographic } \\
\hline Age, years $>65$ & II 4 (28.7) & $60(23.2)$ & $54(39.1)$ & $<0.001$ \\
\hline Gender, Male & $280(70.5)$ & $194(74.9)$ & $86(62.3)$ & 0.012 \\
\hline $\mathrm{BMI}$ & $26.90(24.20,30.25)$ & $26.14(23.48,29.35)$ & $27.82(24.73,32.18)$ & $<0.001$ \\
\hline Initial GCS & $8(3,15)$ & $8(3,15)$ & $7.50(3,13)$ & 0.256 \\
\hline Initial SOFA & $4(3,6)$ & $4(2,5)$ & $4(3,7)$ & 0.011 \\
\hline \multicolumn{5}{|l|}{ Comorbidities } \\
\hline Diabetes & $63(15.9)$ & $34(13.1)$ & $29(21.0)$ & 0.057 \\
\hline $\mathrm{CHF}$ & $46(11.6)$ & $17(6.6)$ & $29(21.0)$ & $<0.001$ \\
\hline Hypertension & $105(26.4)$ & $66(25.5)$ & $39(28.3)$ & 0.633 \\
\hline COPD & $55(13.9)$ & $30(11.6)$ & $25(18.1)$ & 0.101 \\
\hline Coagulation disorder & $37(9.3)$ & $17(6.6)$ & $20(14.5)$ & 0.016 \\
\hline Alcohol abuse & $65(16.4)$ & $48(18.5)$ & $17(12.3)$ & 0.147 \\
\hline \multicolumn{5}{|l|}{ Vital signs } \\
\hline Body Temperature C & $36.4(35.8,37.1)$ & $36.5(35.8,37.1)$ & $36.4(35.8,37.1)$ & 0.487 \\
\hline Heart Rate (beats/minute) & $86(75,102)$ & $86(74,99)$ & $86(75,104)$ & 0.546 \\
\hline Systolic BP (mmHg) & $127.09(25.32)$ & $128.19(25.24)$ & $|25.0|(25.43)$ & 0.233 \\
\hline Diastolic BP (mmHg) & $65(57,77)$ & $66(59,78)$ & $64(53,73)$ & 0.025 \\
\hline MAP (mmHg) & $84(72,96)$ & $85(73,97)$ & $81.67(70,93)$ & 0.084 \\
\hline Respiratory Rate & $17(14,20)$ & $17(14,20)$ & $17(14.25,20)$ & 0.796 \\
\hline $\mathrm{SpO} 2(\%)$ & $100(97,100)$ & $100(97,100)$ & $100(98,100)$ & 0.305 \\
\hline \multicolumn{5}{|l|}{ Arterial blood gas parameters } \\
\hline Base excess & $-2(-5,0)$ & $-2(-5,0)$ & $-I(-5,2)$ & 0.007 \\
\hline Lactate & $2.40(1.70,3.40)$ & $2.40(1.90,3.45)$ & $2.20(1.33,3.40)$ & 0.004 \\
\hline PCO2 (mmHg) & $43(39,48)$ & $43(39,48.50)$ & $43(37.25,47)$ & 0.237 \\
\hline $\mathrm{PH}$ & $7.34(7.28,7.40)$ & $7.34(7.27,7.38)$ & $7.35(7.30,7.42)$ & 0.006 \\
\hline PO2 $(\mathrm{mmHg})$ & $190(107,308)$ & $190(|1| 2,284.50)$ & $190(102.50,319.25)$ & 0.956 \\
\hline Bicarbonate $(\mathrm{mmol} / \mathrm{L})$ & $23(21,26)$ & $23(21,25)$ & $24(22,27)$ & 0.013 \\
\hline Anion Gap & $14(12,16)$ & $14(12,16)$ & $15(13,17)$ & 0.036 \\
\hline \multicolumn{5}{|l|}{ Laboratory test } \\
\hline Albumin (mg/dL) & $3(2.80,3.10)$ & $3(3,3.10)$ & $3(2.50,3)$ & 0.002 \\
\hline Amylase & $59.50(52,65)$ & $59.50(57,70)$ & $59.50(46.50,59.88)$ & 0.082 \\
\hline Creatinine & I $(0.80, \mid .20)$ & I $(0.80, I . I 0)$ & I $(0.80, \mid .30)$ & 0.262 \\
\hline Blood glucose & $136(112,168)$ & I35 (I | 2.50,162) & $139(109,176.25)$ & 0.426 \\
\hline Lipase & $31(26,36)$ & $31(27.50,38)$ & $31(24,32.75)$ & 0.192 \\
\hline Urea nitrogen & $16(12,22)$ & $15(12,20)$ & $17(13,26)$ & 0.015 \\
\hline Hemoglobin (g/dL) & $12.24(2.15)$ & $12.47(2.15)$ & II.80 (2.08) & 0.003 \\
\hline INR & $1.20(1.10,1.40)$ & $1.20(1.10,1.30)$ & $1.20(1.10,1.50)$ & 0.001 \\
\hline Neutrophils (\%) & $81.35(79,83.40)$ & $81.35(79.30,82.95)$ & $81.35(78,83.75)$ & 0.796 \\
\hline Platelet ( 109 /L) & $253(186,319)$ & $250(190,310)$ & $262.50(176.50,342.75)$ & 0.524 \\
\hline PT (seconds) & $13.40(12.70,15)$ & $13.30(12.60,14.50)$ & $13.70(12.80,16.32)$ & 0.007 \\
\hline APTT (seconds) & $26.80(24,32)$ & $26.30(23.70,29.80)$ & $27.70(24.75,34.53)$ & 0.009 \\
\hline WBC (10 9/L) & $12.80(9.40,17.30)$ & $12.70(9.50,17.25)$ & $12.90(9.10,17.45)$ & 0.855 \\
\hline \multicolumn{5}{|l|}{ Outcomes } \\
\hline Sepsis & $198(49.9)$ & $93(35.9)$ & $105(76.1)$ & $<0.001$ \\
\hline Length of EICU stay (day) & $4(2,10)$ & $3(2,8)$ & $6(3,12)$ & 0.001 \\
\hline
\end{tabular}

(Continued) 
Table I (Continued).

\begin{tabular}{|c|c|c|c|c|}
\hline $\begin{array}{l}\text { Characteristics n (\%) } \\
\text { [Mean(SD) or Median, IQR] }\end{array}$ & $\begin{array}{l}\text { Overall } \\
(n=397)\end{array}$ & $\begin{array}{c}\text { Low HbAlc } \\
\text { HbAlc }<6.5 \% \\
(n=259)\end{array}$ & $\begin{array}{c}\text { High HbAlc } \\
\text { HbAlc }>6.5 \% \\
(n=138)\end{array}$ & $p$ \\
\hline Length of hospital stay (day) & $12(6,21)$ & $10(5,18.50)$ & $14(8,25)$ & $<0.001$ \\
\hline 30-day mortality & $60(15.1)$ & $19(7.3)$ & $4 \mathrm{I}(29.7)$ & $<0.001$ \\
\hline
\end{tabular}

Abbreviations: GCS, Glasgow score; SOFA, sequential organ failure assessment; CHF, congestive heart failure; COPD, chronic obstructive pulmonary disease; MAP, mean arterial pressure; INR, international normalized ratio; PT, prothrombin time; APTT, activated partial thromboplastin time; WBC; white blood cell.

factor for death. ${ }^{10}$ Mypinder's study showed that hemoglobin concentrations $<90 \mathrm{~g} / \mathrm{L}$ was associated with increased hospital mortality in patients with severe brain injury. ${ }^{11}$ A retrospective analysis of 12,418 patients showed that hypoalbuminemia is common in patients with acute coronary syndrome, heart failure, cardiac arrest, and cardiogenic shock, and is associated with higher shortterm and long-term mortality. ${ }^{12}$ After adjusting for age, sex, BMI and other covariates, creatinine and HbAlc were independent risk factors for sepsis and increased mortality in trauma patients. We believe that this result may be related to diabetic nephropathy in diabetic patients. Nakanishi's study also suggested an association between renal function and $\mathrm{HbA} 1 \mathrm{c}$, suggesting that $\mathrm{HbA} 1 \mathrm{c}>7.0 \%$ increases the risk of diabetic microangiopathy, which increases the risk of diabetic nephropathy. ${ }^{13}$ In our results, HbA1c was most closely related to blood glucose, so we focused on analyzing the influence of HbA1c on trauma patients. There are some studies on the relationship between blood sugar and trauma prognosis, but the results are not consistent. Studies suggest that hyperglycemia caused by stress and diabetes increases ICU mortality in trauma patients, on the other hand, some research believes that increased mortality occurs only in trauma patients with stress hyperglycemia. It does not occur in trauma patients with hyperglycemia due to diabetes. ${ }^{14,15}$ Study of Edwards supports our conclusion that trauma patients with $\mathrm{HbAlc}$ greater than $6 \%$ at admission had a higher mortality rate than $50 \%$ and ICU hospitalization and mechanical ventilation were significantly higher than those in the HbA1c normal group. ${ }^{16}$ Our findings support the view that HbA1c levels may help predict incidences of sepsis in trauma patients after their admission.

Previous studies have focused on the relationship between HbA1c and sepsis, and it is believed that hyperglycemia is independently associated with poor prognosis, especially in diabetic patients. ${ }^{17,18}$ The study of Baltrusaitis about hand trauma suggests that the wounds were more susceptible to infection in patients with high HbA1c. ${ }^{19}$ The result of Iavazzo study suggests that the increase of preoperative $\mathrm{HbA} 1 \mathrm{c}$ may indicate a higher risk of infection complications and readmission within 30 days in both diabetic and non-diabetic patients. ${ }^{20}$

Our results suggest that pre-admission blood glucose level can be a predictor of sepsis after admission in trauma patients. Patients with high HbAlc were more likely to develop sepsis than patients with low HbA1c (76.1\% vs35.9\%). In the case of inflammatory stimulation due to abnormal regulatory response of the immune system for people with elevated blood glucose, it is noted that lymphocyte reduction rate is increased, and neutrophil, serum CRP and IL- 6 levels were elevated. ${ }^{21}$ These may be the reasons why patients in this study are more likely to develop sepsis.

The effects of hyperglycemia on the patient's physical environment are diverse. The injury of vascular endothelial glycocalyx(VEG) caused by hyperglycemia is considered to be the starting factor of pathological injury such as atherosclerosis, ischemia/reperfusion injury, diabetic complications and the occurrence and development of sepsis. ${ }^{22,23}$ VEG is the first protective layer on the surface of the endothelial surface layer (ESL), which is involved in regulating cell adhesion and migration in an inflammatory state to influence important functions like vascular tension, endothelial permeability, coagulation and thrombosis. Up regulation of endothelin-1 in diabetic patients induces podocyte heparinase, which in turn leads to glomerular VEG injury. $^{24,25}$ With the exception of hyperglycemia, under other pathophysiological conditions such as atherosclerosis, infection, ischemia/reperfusion injury and trauma, ESL can be disrupted to impair endothelial function. ${ }^{26}$ Studies suggest that patients with higher HbAlc levels are more severely damaged than patients with lower HbAlc levels during sepsis. From this perspective, HbAlc itself may play the role of a marker reflecting a chronic hyperglycemic state and suggesting that VEG has been disrupted before trauma occurs. $^{27}$ 
Table 2 Univariate Analysis of Independent Predictors for Sepsis Morbidity of EICU Trauma Patients

\begin{tabular}{|c|c|c|}
\hline & OR ( $95 \% \mathrm{Cl}$ for OR) & p-value \\
\hline Age, years $>65$ & $1.74(1.12 \sim 2.72)$ & 0.014 \\
\hline Gender, Male & $0.63(0.56 \sim 1.28)$ & 0.257 \\
\hline BMI & $1.11(1.07 \sim 1.16)$ & $<0.001$ \\
\hline DM & $3.93(2.16 \sim 7.5 \mathrm{I})$ & $<0.001$ \\
\hline $\mathrm{CHF}$ & $5.67(2.7 \sim|3.4|)$ & $<0.001$ \\
\hline Hypertension & $2.29(1.45 \sim 3.66)$ & $<0.001$ \\
\hline COPD & $2.81(1.54 \sim 5.34)$ & 0.001 \\
\hline Coagulation disorder & $3.48(1.66 \sim 8)$ & 0.002 \\
\hline Alcohol abuse & $0.78(0.45 \sim 1.32)$ & 0.355 \\
\hline Body Temperature ${ }^{\circ} \mathrm{C}$ & $0.96(0.8 \sim 1.15)$ & 0.647 \\
\hline Heart Rate (beats/minute) & $\mathrm{I}(0.99 \sim 1.0 \mathrm{I})$ & 0.521 \\
\hline Systolic BP (mmHg) & $0.99(0.98 \sim 1)$ & 0.006 \\
\hline Diastolic BP (mmHg) & $0.99(0.98 \sim 1)$ & 0.086 \\
\hline MAP (mmHg) & $0.99(0.98 \sim 1)$ & 0.074 \\
\hline Respiratory Rate (beats/minute) & $1.01(0.98 \sim 1.05)$ & 0.446 \\
\hline $\mathrm{SpO} 2(\%)$ & $0.95(0.9 \sim 1)$ & 0.065 \\
\hline Initial GCS & $0.94(0.9 \sim 0.98)$ & 0.003 \\
\hline Initial SOFA & $1.25(1.14 \sim 1.37)$ & $<0.001$ \\
\hline Base excess $(\mathrm{mmol} / \mathrm{L})$ & $1.03(I \sim 1.08)$ & 0.075 \\
\hline Lactate $(\mathrm{mmol} / \mathrm{L})$ & $0.95(0.87 \sim 1.03)$ & 0.206 \\
\hline $\mathrm{PCO} 2(\mathrm{mmHg})$ & $1.01(0.99 \sim 1.03)$ & 0.251 \\
\hline $\mathrm{PH}$ & $1.95(0.36 \sim 10.82)$ & 0.438 \\
\hline $\mathrm{PO} 2(\mathrm{mmHg})$ & I $(I \sim 1)$ & 0.694 \\
\hline Bicarbonate $(\mathrm{mmol} / \mathrm{L})$ & $1.06(I \sim 1 . I I)$ & 0.039 \\
\hline Anion Gap (mmol/L) & $1.02(0.96 \sim 1.08)$ & 0.506 \\
\hline Albumin (g/dL) & $0.65(0.44 \sim 0.94)$ & 0.025 \\
\hline Amylase (IU/I) & I $(I \sim 1)$ & 0.808 \\
\hline Creatinine (mg/dL) & 2.37 (I.49 4.09) & 0.001 \\
\hline Blood glucose $(\mathrm{mg} / \mathrm{dL})$ & $\mathrm{I}(\mathrm{I} \sim \mathrm{I} .0 \mathrm{I})$ & 0.045 \\
\hline Lipase (IU/L) & $I(I \sim 1)$ & 0.524 \\
\hline Urea nitrogen $(\mathrm{mg} / \mathrm{dL})$ & $1.03(1.01 \sim 1.05)$ & 0.001 \\
\hline Hemoglobin $(\mathrm{g} / \mathrm{dL})$ & $0.83(0.75 \sim 0.9 \mathrm{I})$ & $<0.001$ \\
\hline INR & $1.54(1.16 \sim 2.16)$ & 0.007 \\
\hline Neutrophils (\%) & $0.98(0.96 \sim 1.01)$ & 0.156 \\
\hline Platelet $\left(10^{9} / \mathrm{L}\right)$ & $I(I \sim 1)$ & 0.003 \\
\hline PT (seconds) & 1.01 (0.99 1.03) & 0.455 \\
\hline APTT (seconds) & I.0I (I I.02) & 0.056 \\
\hline WBC $\left(10^{9} / \mathrm{L}\right)$ & I $(0.97 \sim 1.03)$ & 0.871 \\
\hline $\mathrm{HbAlc}>6.5 \%$ & $5.68(3.6 \sim 9.16)$ & $<0.001$ \\
\hline
\end{tabular}

Abbreviations: GCS, Glasgow score; SOFA, sequential organ failure assessment; $\mathrm{CHF}$, congestive heart failure; COPD, chronic obstructive pulmonary disease; MAP, mean arterial pressure; INR, international normalized ratio; PT, prothrombin time; APTT, activated partial thromboplastin time; WBC, white blood cell; BMI, body mass index.

VEG shedding may lead to a series of adverse consequences. First, VEG damage activates and enhances the activity of inflammatory cells. Study has shown that the shedding of VEG exposes the surface adhesion molecules of vascular endothelial cells, which makes inflammatory cells such as neutrophils and mononuclear-macrophages
Table 3 Multivariate Analysis of Independent Predictors for Sepsis of EICU Trauma Patients

\begin{tabular}{|c|c|c|}
\hline & OR (95\% Cl for OR) & p-value \\
\hline \multicolumn{3}{|l|}{ Complicated with } \\
\hline Diabetes & $3.1(1.4 I-6.79)$ & 0.005 \\
\hline Hypertension & $2.55(1.35-4.82)$ & 0.004 \\
\hline Coagulation disorder & $3.45(1.23-9.67)$ & 0.018 \\
\hline $\mathrm{HbAlc}>6.5 \%$ & $2.05(1.65-2.54)$ & $<0.001$ \\
\hline Creatinine (per Img/dL) & $3.7 \mid(|.66-8.3|)$ & $<0.001$ \\
\hline Urea nitrogen (per Img/dL) & $0.96(0.92-0.99)$ & 0.021 \\
\hline Platelet (per $1 \times 10^{9} / \mathrm{L}$ ) & $I(I-I)$ & 0.083 \\
\hline Initial GCS (Upper by I) & $0.93(0.88-0.99)$ & 0.015 \\
\hline BMI & $1.08(1.03-1.13)$ & 0.001 \\
\hline
\end{tabular}

Abbreviations: GCS, Glasgow score; BMI, body mass index.

easier to adhere to endothelial cells, and further transendothelium migration to the tissue space outside the vessel leads to inflammatory dispersal. ${ }^{28}$ In addition to the inflammatory response, VEG injury can destroy the tight junction between endothelial cells, the structural integrity of endothelial cells will become loose. ${ }^{29}$ ARDS caused by pulmonary edema is one of the main causes of death in trauma patients, especially in the elderly. ${ }^{30}$ After VEG injury, the fluid flow in the capillaries greatly exceeds reabsorption, leading to interstitial edema and local ischemia, accelerating tissue ischemia, which eventually leads

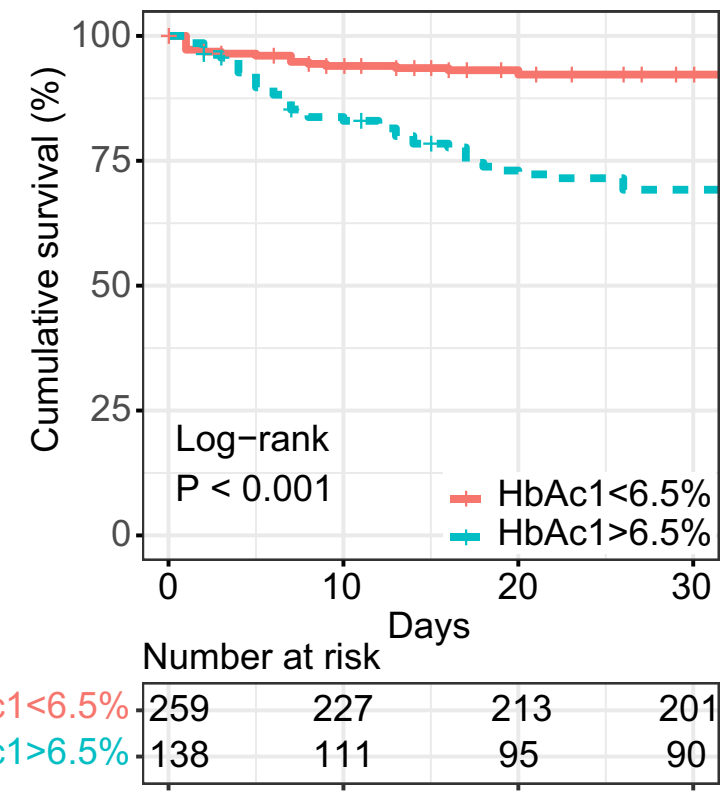

Figure 2 Kaplan-Meier survival curves categorized by HbAlc. 
Table 4 Univariate Analysis of Independent Predictors for EICU Trauma Patients' Mortality

\begin{tabular}{|c|c|c|}
\hline & $\mathrm{HR}(95 \% \mathrm{Cl}$ for $\mathrm{HR})$ & p-value \\
\hline Age, years $>65$ & $5.2(3.4-7.8)$ & $<0.001$ \\
\hline Gender, Male & $0.5 I(0.34-0.76)$ & 0.001 \\
\hline BMI & $0.99(0.96-1)$ & 0.400 \\
\hline DM & I $(0.6|-| .7)$ & 0.920 \\
\hline $\mathrm{CHF}$ & $4.5(2.9-7.1)$ & $<0.001$ \\
\hline Hypertension & $0.97(0.6 \mathrm{I}-1.5)$ & 0.890 \\
\hline COPD & $1.7(1.1-2.8)$ & 0.024 \\
\hline Coagulation disorder & $3.5(2.2-5.7)$ & $<0.001$ \\
\hline Alcohol abuse & $0.67(0.37-1.2)$ & 0.190 \\
\hline Body Temperature ${ }^{\circ} \mathrm{C}$ & $0.85(0.7 I-1)$ & 0.084 \\
\hline Heart Rate (beats/minute) & I (0.99-I) & 0.490 \\
\hline Systolic BP (mmHg) & I (0.99-I) & 0.500 \\
\hline Diastolic BP $(\mathrm{mmHg})$ & $0.98(0.97-0.99)$ & 0.007 \\
\hline MAP $(\mathrm{mmHg})$ & $0.99(0.98-1)$ & 0.140 \\
\hline Respiratory Rate (beats/minute) & $0.98(0.94-1)$ & 0.320 \\
\hline $\mathrm{SpO} 2(\%)$ & $0.98(0.94-I)$ & 0.160 \\
\hline Initial GCS & $0.99(0.95-1)$ & 0.640 \\
\hline Initial SOFA & $1.2(1.1-1.3)$ & $<0.001$ \\
\hline Base excess $(\mathrm{mmol} / \mathrm{L})$ & I.I (I-I.I) & 0.010 \\
\hline Lactate $(\mathrm{mmol} / \mathrm{L})$ & I (0.94-I.I) & 0.550 \\
\hline $\mathrm{PCO} 2(\mathrm{mmHg})$ & $0.97(0.94-I)$ & 0.023 \\
\hline $\mathrm{PH}$ & $22(2.8-180)$ & 0.003 \\
\hline PO2 (mmHg) & $I(I-I)$ & 0.270 \\
\hline Bicarbonate $(\mathrm{mmol} / \mathrm{L})$ & I.I (I-I.I) & 0.002 \\
\hline Anion Gap (mmol/L) & I (0.97-I.I) & 0.270 \\
\hline Albumin $(g / d L)$ & $0.45(0.31-0.64)$ & $<0.001$ \\
\hline Amylase (IU/I) & I (0.99-I) & 0.520 \\
\hline Creatinine $(\mathrm{mg} / \mathrm{dL})$ & I.3 (I.2-I.5) & $<0.001$ \\
\hline Blood glucose $(\mathrm{mg} / \mathrm{dL})$ & $I(I-I)$ & 0.900 \\
\hline Lipase (IU/L) & $I(1-1)$ & 0.770 \\
\hline Urea nitrogen $(\mathrm{mg} / \mathrm{dL})$ & $I(1-1)$ & $<0.001$ \\
\hline Hemoglobin $(g / d L)$ & $0.8(0.73-0.87)$ & $<0.001$ \\
\hline INR & I.3 (I.2-I.4) & $<0.001$ \\
\hline Neutrophils (\%) & I (0.99-I) & 0.300 \\
\hline Platelet (I09/L) & $I(1-1)$ & 0.350 \\
\hline PT (seconds) & $I(1-1)$ & 0.160 \\
\hline APTT (seconds) & $I(I-1)$ & $<0.001$ \\
\hline WBC (109/L) & I (0.97-I) & 0.980 \\
\hline $\mathrm{HbAlc}>6.5 \%$ & $4.7(3.1-7.2)$ & $<0.001$ \\
\hline
\end{tabular}

Abbreviations: GCS, Glasgow score; SOFA, sequential organ failure assessment; $\mathrm{CHF}$, congestive heart failure; COPD, chronic obstructive pulmonary disease; MAP, mean arterial pressure; INR, international normalized ratio; PT, prothrombin time; APTT, activated partial thromboplastin time; WBC, white blood cell; BMI, body mass index.

to organ dysfunction. ${ }^{31}$ All above mentioned mechanisms shown in Figure 3 lead to an increase in the incidence of sepsis and mortality in trauma patients with high HbAlc. In addition to our research, there are other studies on the above mechanism. Maranon et al showed that the levels of mitochondrial reactive oxygen species (mtROS), TNF- $\alpha$,
Table 5 Multivariate Analysis of Independent Predictors for EICU Trauma Patients' Mortality

\begin{tabular}{|l|l|l|}
\hline & HR(95\% CI for HR) & p-value \\
\hline Gender, Male & $1.94(1.21-3.12)$ & 0.006 \\
HbAIc >6.5\% & $1.45(1.32-1.6)$ & $<0.00 \mathrm{I}$ \\
Albumin (per Ig/dL) & $0.54(0.34-0.86)$ & 0.010 \\
Creatinine (per Img/dL) & $1.02(1.01-1.03)$ & 0.004 \\
APTT (per Iseconds) & $1.02(1.01-1.03)$ & $<0.00 \mathrm{I}$ \\
Initial SOFA (Upper by I) & $1.2(1.1-1.3 \mathrm{I})$ & $<0.00 \mathrm{I}$ \\
Age, years>65 & $3.21(1.95-5.3)$ & $<0.00 \mathrm{I}$ \\
\hline
\end{tabular}

Abbreviations: SOFA, sequential organ failure assessment; APTT, activated partial thromboplastin time.

IL-6, in peripheral blood in patients $\mathrm{HbA} 1 \mathrm{c}>6.5 \%$ were significantly higher than those in $\mathrm{HbA} 1 \mathrm{c}<6.5 \%$, and these inflammatory factors may be induced by thioredoxin activation of NF- $\mathrm{kB}$ and expression of inflammatory cytokines. In addition, reactive oxygen species can lead to lipid peroxidation; amplify the inflammatory cascade, eventually leading to cell death and more serious inflammatory response. ${ }^{32}$ Study of Chin has found that acute hyperglycemia can induce sodium-potassium-chloride cotransporter 1(NKCC1) expression by activating serum glucocorticoid kinase 1-NKCC1 pathway, affect alveolar fluid regulation, and aggravate lung injury. ${ }^{33}$

To our knowledge, this is the first study to assess the relationship between $\mathrm{HbAlc}$ levels and sepsis occurrence and mortality in emergency trauma patients. This study revealed the relationship between $\mathrm{HbA} 1 \mathrm{c}$ levels and ICU mortality in trauma patients. Kaplan-Meier analysis showed that the survival time of patients with high HbAlc was significantly shorter than that of patients with low $\mathrm{HbAlc}$. We conclude that $\mathrm{HbAlc}$ greater than $6.5 \%$ is associated with increased mortality in EICU patients. META analysis, which included 57 RCT studies in 2020, suggests that intense blood glucose control can reduce all-cause mortality in ICU patients compared with routine blood glucose control. ${ }^{34}$ The relationship between previous blood glucose levels and blood glucose control levels during treatment and mortality in trauma patients still needs further study.

There are some limitations for this study adopting retrospective design, and the total number of trauma patients included in this study was small because detection of HbAlc levels was not a common blood test in emergency trauma patients unless they had been explicitly diagnosed with diabetes or provided with a history of diabetes. 


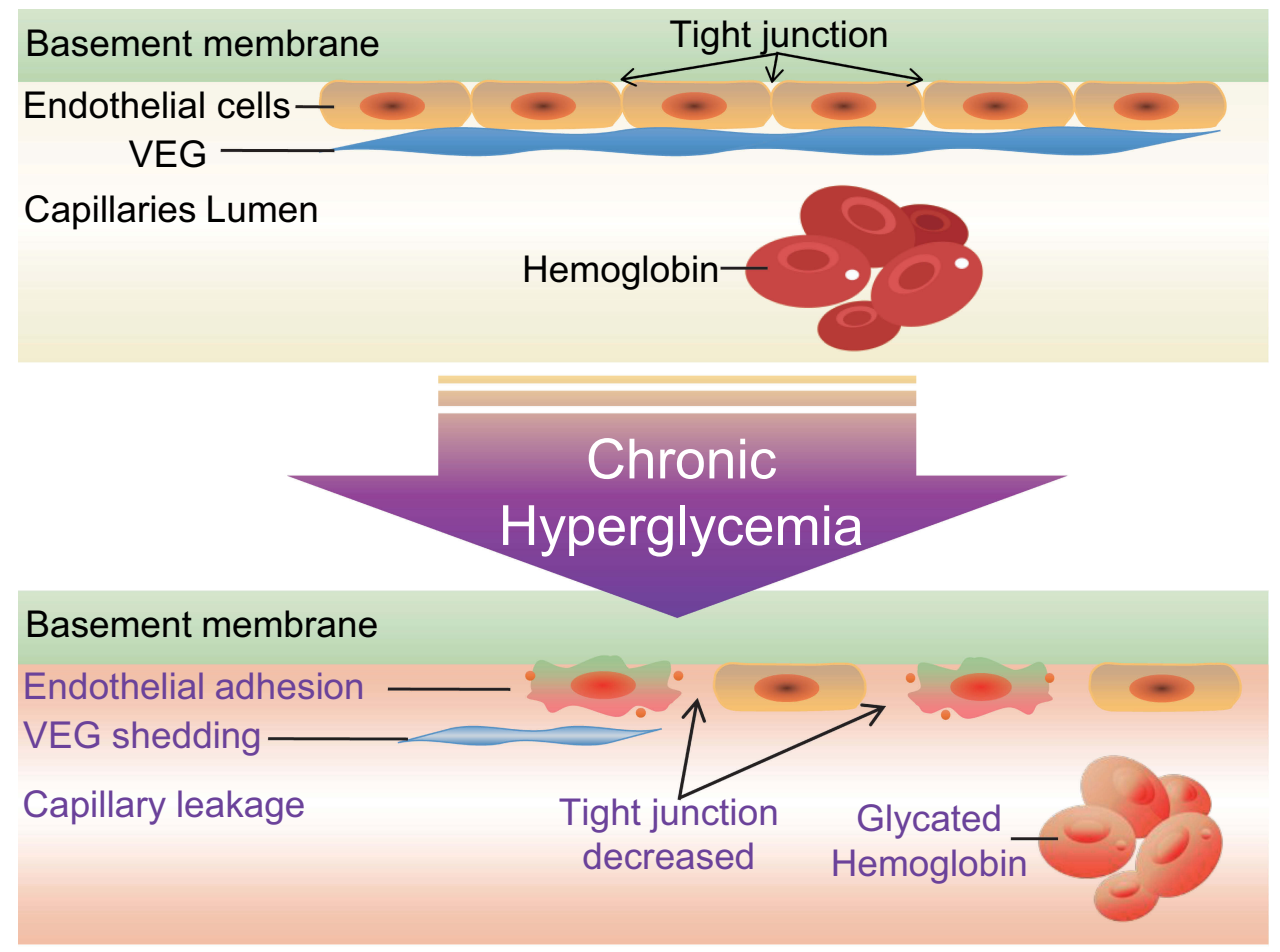

Figure 3 Chronic hyperglycemia caused VEG shedding and adverse consequences.

The results of this study emphasize the importance of HbAlc detection in trauma patients, but also the importance of blood glucose management. In clinical practice, we should pay more attention to trauma patients with high $\mathrm{HbA1c}$, strengthen care, and carefully formulate treatment plans to prevent sepsis from threatening lives.

\section{Conclusions}

In patients with trauma, the HbA1c level at EICU admission is associated with both sepsis incidence and mortality. It may be important to assess HbA1c level at EICU admission because it may be a predictor of emergency trauma patients' outcome. For patients with a high HbAlc level $(>6.5 \%)$, greater attention should be paid to the possibility of septic progression.

\section{Data Sharing Statement}

The dataset referenced in this study can be obtained from the corresponding author according to reasonable requirements.

\section{Ethical Approval and Consent for Participation}

This study was approved by the ethics review committee (KYDWCS2019150) of Shengjing hospital affiliated to China Medical University. This study was limited to the secondary use of data collected in daily practice in the past, and the identity of the patient was completely unidentifiable, so no informed consent was required.

\section{Author Contributions}

Both authors made a significant contribution to the work reported, whether that is in the conception, study design, execution, acquisition of data, analysis and interpretation, or in all these areas; took part in drafting, revising or critically reviewing the article; gave final approval of the version to be published; have agreed on the journal to which the article has been submitted; and agree to be accountable for all aspects of the work.

\section{Funding}

This study was supported by funding from the Science Foundation of Liaoning Education Department (no. FWZR2020012) and the 345 Talent Project of Sheng Jing Hospital.

\section{Disclosure}

The authors reported no conflicts of interest for this work. 


\section{References}

1. The Lancet. Trauma: a neglected US public health emergency. Lancet. 2016;388(10056):2058.

2. Zeng L, Du J, Gu W, et al. Rs1800625 in the receptor for advanced glycation end products gene predisposes to sepsis and multiple organ dysfunction syndrome in patients with major trauma. Crit Care. 2015;19(1):6. doi:10.1186/s13054-014-0727-2

3. Gabriel V, Grigorian A, Nahmias J, et al. Risk factors for post-operative sepsis and septic shock in patients undergoing emergency surgery. Surg Infect. 2019;20(5):367-372. doi:10.1089/sur.20 18.186

4. Critchley JA, Carey IM, Harris T, DeWilde S, Hosking FJ, Cook DG. Glycemic control and risk of infections among people with type 1 or type 2 diabetes in a large primary care cohort study. Diabetes Care. 2018;41(10):2127-2135. doi:10.2337/dc18-0287

5. Dorcely B, Katz K, Jagannathan R, et al. Novel biomarkers for prediabetes, diabetes, and associated complications. Diabetes Metab Syndr Obes. 2017;10:345-361. doi:10.2147/DMSO.S100074

6. Lee J, Oh JS, Zhu JH, et al. High HbAlc is associated with decreased 6-month survival and poor outcomes after out-of-hospital cardiac arrest: a retrospective cohort study. Scand J Trauma Resusc Emerg Med. 2020;28(1):88. doi:10.1186/s13049-020-00782-1

7. Jehan F, Joseph B. Perioperative glycemic control and postoperative complications in patients undergoing emergency general surgery: what is the role of HbA1c? J Trauma Acute Care Surg. 2019;86 (2):379. doi:10.1097/TA.0000000000002116

8. Luethi N, Cioccari L, Tanaka A, et al. Glycated hemoglobin A1c levels are not affected by critical illness. Crit Care Med. 2016;44 (9):1692-1694. doi:10.1097/CCM.0000000000001656

9. Singer M, Deutschman CS, Seymour CW, et al. The third international consensus definitions for sepsis and septic shock (sepsis-3) JAMA. 2016;315(8):801-810. doi:10.1001/jama.2016.0287

10. Mitra B, Tullio F, Cameron PA, Fitzgerald M. Trauma patients with the 'triad of death'. Emerg Med J. 2012;29(8):622-625. doi:10.1136/ emj.2011.113167

11. Sekhon MS, McLean N, Henderson WR, Chittock DR, Griesdale DE. Association of hemoglobin concentration and mortality in critically ill patients with severe traumatic brain injury. Crit Care. 2012;16(4): R128. doi:10.1186/cc11431

12. Padkins M, Breen T, Anavekar N, Barsness G, Kashani K, Jentzer JC. Association between albumin level and mortality among cardiac intensive care unit patients. $J$ Intensive Care Med. 2020;885066620963875. doi:10.1177/0885066620963875

13. Nakanishi S, Hirukawa H, Shimoda M, et al. Comparison of HbA1c levels and body mass index for prevention of diabetic kidney disease: a retrospective longitudinal study using outpatient clinical data in Japanese patients with type 2 diabetes mellitus. Diabetes Res Clin Pract. 2019;155:107807. doi:10.1016/j.diabres.2019.107807

14. Chang MW, Huang CY, Liu HT, Chen YC, Hsieh CH. Stress-induced and diabetic hyperglycemia associated with higher mortality among intensive care unit trauma patients: cross-sectional analysis of the propensity score-matched population. Int $J$ Environ Res Public Health. 2018;15(5):992. doi:10.3390/ijerph15050992

15. Rau CS, Wu SC, Chen YC, et al. Higher mortality in trauma patients is associated with stress-induced hyperglycemia, but not diabetic hyperglycemia: a cross-sectional analysis based on a propensity-score matching approach. Int $J$ Environ Res Public Health. 2017;14(10):1161

16. Edwards JD, Flood DMN, Bayouth LA, et al. Assessing risk for mortality in trauma: the value of admission hemoglobin A1c. $\mathrm{Am}$ Surg. 2020;86(9):1094-1097. doi:10.1177/0003134820943562
17. Yo CH, Lee MT, Gi WT, et al. Prognostic determinants of community-acquired bloodstream infection in type 2 diabetic patients in ED. Am J Emerg Med. 2014;32(12):1450-1454. doi:10.1016/j. ajem.2014.08.071

18. Zohar Y, Zilberman Itskovich S, Koren S, Zaidenstein R, Marchaim D, Koren R. The association of diabetes and hyperglycemia with sepsis outcomes: a population-based cohort analysis. Intern Emerg Med. 2021;16(3):719-728. doi:10.1007/s11739-020-02507-9

19. Estrella EP, Lee EY. Risk factors for hand wound infections in people with diabetes: a case-control study. Wound Manag Prev. 2019;65 (8):38-43. doi:10.25270/wmp.2019.8.3843

20. Iavazzo C, McComiskey M, Datta M, et al. Preoperative HBA1c and risk of postoperative complications in patients with gynaecological cancer. Arch Gynecol Obstet. 2016;294(1):161-164. doi:10.1007/ s00404-015-3983-8

21. Zhu L, She ZG, Cheng X, et al. Association of blood glucose control and outcomes in patients with COVID-19 and pre-existing type 2 diabetes. Cell Metab. 2020;31(6):1068-1077.e1063. doi:10.1016/j. cmet.2020.04.021

22. Alphonsus CS, Rodseth RN. The endothelial glycocalyx: a review of the vascular barrier. Anaesthesia. 2014;69(7):777-784. doi:10.1111/ anae. 12661

23. Iba T, Levy JH. Derangement of the endothelial glycocalyx in sepsis. J Thromb Haemost. 2019;17(2):283-294. doi:10.1111/jth.14371

24. Goligorsky MS. Vascular endothelium in diabetes. Am J Physiol Renal Physiol. 2017;312(2):F266-f275. doi:10.1152/ajprenal.00473.2016

25. Huang X, Hu H, Sun T, et al. Plasma endothelial glycocalyx components as a potential biomarker for predicting the development of disseminated intravascular coagulation in patients with sepsis. J Intensive Care Med. 2020;885066620949131.

26. Sieve I, Münster-Kühnel AK, Hilfiker-Kleiner D. Regulation and function of endothelial glycocalyx layer in vascular diseases. Vascul Pharmacol. 2018;100:26-33. doi:10.1016/j.vph.2017.09.002

27. Lee YS, Min KH, Lee SY, et al. The value of glycated hemoglobin as predictor of organ dysfunction in patients with sepsis. PLoS One. 2019;14(5):e0216397. doi:10.1371/journal.pone.0216397

28. Lever R, Rose MJ, McKenzie EA, Page CP. Heparanase induces inflammatory cell recruitment in vivo by promoting adhesion to vascular endothelium. Am J Physiol Cell Physiol. 2014;306(12): C1184-C1190. doi:10.1152/ajpcell.00269.2013

29. Gill SE, Rohan M, Mehta S. Role of pulmonary microvascular endothelial cell apoptosis in murine sepsis-induced lung injury in vivo. Respir Res. 2015;16(1):109. doi:10.1186/s12931-015-0266-7

30. Killien EY, Mills B, Vavilala MS, Watson RS, O'Keefe GE, Rivara FP. Association between age and acute respiratory distress syndrome development and mortality following trauma. $J$ Trauma Acute Care Surg. 2019;86(5):844-852. doi:10.1097/TA.0000000000002202

31. Lupu F, Kinasewitz G, Dormer K. The role of endothelial shear stress on haemodynamics, inflammation, coagulation and glycocalyx during sepsis. J Cell Mol Med. 2020;24(21):12258-12271. doi:10.1111/jcmm.15895

32. de Marañón AM, Iannantuoni F, Abad-Jiménez Z, et al. Association between proinflammatory markers, leukocyte-endothelium interactions, and carotid intima-media thickness in type 2 diabetes: role of glycemic control. J Clin Med. 2020;9(8):2522. doi:10.3390/ jcm9082522

33. Wu CP, Huang KL, Peng CK, Lan CC. Acute hyperglycemia aggravates lung injury via activation of the SGK1-NKCC1 pathway. Int J Mol Sci. 2020;21(13). doi:10.3390/ijms21134803

34. Yao RQ, Ren C, Wu GS, Zhu YB, Xia ZF, Yao YM. Is intensive glucose control bad for critically ill patients? A systematic review and meta-analysis. Int $J$ Biol Sci. 2020;16(9):1658-1675. doi:10.7150/ijbs. 43447 


\section{Publish your work in this journal}

Infection and Drug Resistance is an international, peer-reviewed openaccess journal that focuses on the optimal treatment of infection (bacterial, fungal and viral) and the development and institution of preventive strategies to minimize the development and spread of resistance. The journal is specifically concerned with the epidemiology of antibiotic resistance and the mechanisms of resistance development and diffusion in both hospitals and the community. The manuscript management system is completely online and includes a very quick and fair peerreview system, which is all easy to use. Visit http://www.dovepress.com/ testimonials.php to read real quotes from published authors.

Submit your manuscript here: https://www.dovepress.com/infection-and-drug-resistance-journal 